\title{
Searching for Bliss:
}

\section{Insights and challenges in yoga and contemporary}

\author{
dance choreography
}

\author{
Karen Barbour \\ The University of Waikato
}

\begin{abstract}
In this article I discuss a research project exploring how yoga-based movement motifs might be developed within choreography for performance, while retaining a focus on wellbeing for all involved. In attending to our wellbeing, I consider creative processes, preparation, rehearsals, sequencing of the movements in the choreography and the choice of specific yoga movements. Within the process of creating two dance works, a number of insights and challenges arose relating to our diverse and shared understandings of wellbeing, and also our integrity in performance. Drawing on research findings in the form of dancers' reflections, images from the performances, my choreographer's journal notes and our embodied methodology, I combine different representational methods to share some of these insights and challenges.
\end{abstract}

\section{INTRODUCTION}

Undertaking research over the last five years, I have been delving deeper into the integration of yoga within contemporary dance practice, in both choreography and in my tertiary teaching (Barbour, 2011, 2013). A combination of small research projects has provided me with greater insight and practical knowledge about yoga within pedagogy and performance. As brief background, over the last 20 years I have been a student of yoga, particularly lyengar yoga and more recently, Astanga

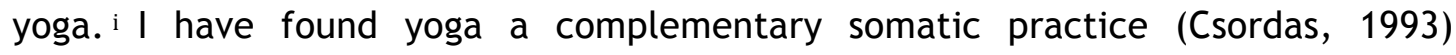
alongside my contemporary dance training and a means of enhancing my own wellbeing. The value of yoga as a method of embodied knowing and as a means of developing functional integrity in contemporary dance through enhanced body awareness, strength and flexibility parallels the value of the emotional awareness, intention and focus I observe in my personal life (Barbour, 2011, 2013).

Working as a feminist educator and artist, I undertake research with a feminist and phenomenological perspective, investigating lived embodied 
experience. My agenda is to reconstruct knowledge with a feminist consciousness of contemporary socio-cultural and political issues for women. In particular, I am interested in researching women's embodied knowledge, validating embodied insights and women's expressions of their knowledge in dancing (Barbour, 2011). Aligned with the complementary approaches of creative practice research in choreography and performance, I have adopted and developed relevant methodologies for this research, making regular use of a range of methods including interviews, structured group discussions, documentary images, improvisational and choreographic research methods, reflective questioning and journal writing. In each case, when employing these methods I am cognizant of issues of power, trust, rapport, empathy, voice, subjectivity and reflexivity within research. ii Awareness of these issues is especially key in embodied practicesworkshops involving improvisation and choreography, rehearsals, performances-as well as in reflection. My research methodology reflects a feminist ethic of care in which functioning relationships, respect and reciprocity are important moral concerns, along with consideration of self-determination, transformation and empowerment (Noddings, 2003). With gratitude I acknowledge dance artists Patti, Alex, Caterina, Emma, Helene and Marie with whom I am privileged to work and who are participants in this research. ${ }^{i i i}$

Within this article, I refer to experiences relating to two performance works: Dancing through paradise, performed in 2010 in the Indian Char Bagh Garden within the Hamilton Gardens Arts Festival in New Zealand (February 2010); and Bliss, also performed in the Indian Char Bagh Garden in the 2013 festival (February 2013). The Hamilton Gardens Arts Festival is an annual summer arts festival that brings our celebrated city gardens alive with vibrant and unique music, theatre, dance, street theatre, picnics, art exhibitions and presentations for all ages (Barbour, 2010; Barbour \& Hitchmough, 2013; Doube, 2007; Sergel, 2004). The Indian Char Bagh Garden, the site for these performance works, is an enclosed four-part garden with a central fountain, modelled on the ancient 'paradise' gardens common throughout the Muslim world and in India. Such gardens were designed for relaxation and enjoyment of the sensuous pleasures offered by the sight and scents of the flowering beds, the tinkling fountain and pools (Barbour, 2010; Sergel, 2004).

It is significant that these performance works were site-specific and created for the (arguably) 'therapeutic' landscape of the Indian Char Bagh Garden. This garden, like other meditative, retreat and contemplation gardens in general, is 
potentially able to foster healing and restorative affects through active engagement with the environment (Gesler, 2003; Lea, 2008). In this sense, undertaking a creative process in such gardens might enhance general wellbeing simply as a result of actively being there. Perhaps, in taking the body away from the everyday environments in which we live and work, we are able to open up "attention to the body itself, foregrounding its connections to the world" (Lea, 2008, p. 95). However, as Jennifer Lea argues, spending time in such places “does not tell us how we should live, but rather acts to problematise our existent modes of dwelling" (2008, p. 96, italics original). Thus, while the garden environment may possibly impact on our wellbeing directly, it may also prompt further valuable reflection about the nature of wellbeing in our everyday lives. In this article I refer to the specific site of the garden in relation to our embodied experiences and issues of wellbeing. However I do not directly focus on the nature and processes of site-specific choreography and performance.iv

Discussion will focus on insights within the creative process, considering methods of preparation, rehearsals, sequencing and specific yoga āsana (postures or poses). Quoting the dancers' reflections on their experiences, I discuss specific challenges we faced and related insights including emerging experiences of bliss within performances. Before doing so, I contextualize this research by reviewing broad understandings of yoga and wellbeing in the research literature.

\section{YOGA AND WELLBEING}

The potential for yoga practice to enhance wellbeing in general is both commonly acknowledged in the practices of yoga and documented in the extensive writing about the histories of yoga over the last 2000 years. In general, yoga is understood to mean to yoke, join or bind the conscious attention of the mind and the body (Desikachar, 1995; Fraleigh, 2009; lyengar, 1994). Some of the broader philosophies of yoga are explicated in the Yoga Sutras, the classic work compiled by Patanjali, and expressed through the eight limbs of yoga (Desikachar, 1995; lyengar, 1994). The eight limbs or stages of yoga incorporate:

1. Yama (universal moral commandments); 2. Niyama (self-purification by discipline); 3. Āsana (posture); 4. Prānāyāma (rhythmic control of the breath); 5. Pratyāhāra (withdrawal and emancipation of the mind from the dominations of the senses and exterior objects); 6. Dhārana (concentration); 7. Dhyāna (meditation) and 8. Samādhi (a state of 
super-consciousness brought about by profound meditation. (lyengar, 1994, p. 21)

These practices of yoga and understandings of wellbeing are embedded in Indian philosophies and cultures, involving a lifetime of enculturation, which students of yoga like myself obviously lack. Thus, rather than discuss yoga philosophies from my perspective as a beginner and outsider, I refer to Mahadev Desai, who, in stating that yoga offers "a poise of the soul which enables one to look at life in all its aspects evenly" (Desai, cited in lyengar, 1994, p. 19), encapsulates my philosophical approach to yoga.

Two particular sources of learning for me come through yoga practitioners who work outside India-the writings and teachings of yogi BKS lyengar and the work of dance phenomenologist and somatics educator Sondra Fraleigh. Iyengar offers a perspective of yoga through his extensive writings and teaching as "the method by which the restless mind is calmed and the energy directed into constructive channels (1994, p. 20). Sondra Fraleigh, a dance, yoga and somatic practitioner who has also published and taught extensively around the world, summarizes that yoga had the ... original intent of spiritual healing and selfawareness ... it signals our kinship with the environment and all forms of life. In practice, yoga can be a psychophysical means for transforming personality ..." (Fraleigh, 2009, p. xi). Both these perspectives on yoga provide a basis for my experiences of yoga as an embodied way of knowing and a means for enhancing wellbeing.

In the varied forms of general health research, wellbeing is understood as incorporating various dimensions (Cardinal, 2014; Dodge, Daly, Huyton, \& Sanders, 2012; Durie, 1994; World Health Organisation, 1997). In particular, in Aotearoa New Zealand we discuss physical aspects or taha tinana, referring to bodily growth, development, care and movement in our lives; mental and emotional aspects or taha hinengaro, referring to coherent thoughts, expression and responsiveness; social aspects or taha whānau, referring to family, friendships and relationships with others, as well as feelings of belonging, compassion, caring and support; and spiritual dimensions of health or taha wairua, referring to our searches for meaning and purpose, identity and self-awareness (Durie, 1994; World Health Organisation, 1997). Further, and specifically in relation to the context of dance, wellness has be considered in relation to social, physical, intellectual, career, emotional, environmental and spiritual dimensions or aspects (Cardinal, 2014). While descriptions and definitions of wellbeing continue to be debated academically, I 
appreciate a recent interpretation of wellbeing as "a sort of dynamic dance" in which each person embodies a balancing between their resources and the challenges they face (Marks cited in Dodge et al., 2012, p. 230). In this sense, wellbeing is an integrated, embodied and multi-dimensional experience.

When considering these holistic notions of wellbeing commonly referred to in Aotearoa, the philosophies and practices of yoga relate to and can contribute to these holistic understandings. While it is relevant to note that the philosophies of yoga do not explicitly include social aspects or taha whānau, the practices of yoga may contribute to a sense of social and community identity and belonging (Lewis, 2008), and the first limb of yoga-Yama or universal moral commandments (lyengar, 1994)-suggests shared social and moral understandings. Clearly yoga philosophies have a relationship to multi-dimensional understandings of wellbeing, although this may not be explicit in the practice of yoga in all Western contexts (Lewis, 2008; Santillano, 2006). As Clara Lewis (2008) argues, there is a substantial ontological difference in the holistic understandings of health and wellbeing in yoga and the physical notion of health as absence of disease, typical in Western medicine.

I appreciate the holistic nature of yoga practice personally as a student of yoga and a dancer, although I have observed that it is often the physical practice of āsana that dancers appear to respond most to, at least initially (Barbour, 2013; Santillano, 2006). There are a few writers investigating the relationship of yoga practice and dance (for example Bennett, 2002; Dalzell, 2011; Enghausser, 2007; Fraleigh, 2009; Gold, 2013; Hartley, 1989; Santillano, 2006). Many practitioners are involved in teaching integrated forms of yoga and dance along with other somatic practices. Within tertiary education and professional dance practice internationally, different forms of yoga are often integrated with dance training and dancers also are regular participants in yoga classes (Barbour, 2013; Gold, 2013; Hartley, 1989; Santillano, 2006). In recent years when offering contemporary dance classes that integrate yoga, I have asked the dancers the question of how they understand wellbeing (Barbour, 2011, 2013). The experience of searching for balance and the need for movement or dance within their lives are common responses (Barbour, 2011). I am interested to engage dancers in the physical practices, the āsana and vinyasa (flowing sequences), the breathing, and also to foster the accompanying quieting of the mind that may emerge in moving meditations. Further, I see the potential that a sense of emotional balance and spiritual connection may arise for dancers through yoga. 
However, many yoga gurus, teachers and writers argue that the holistic nature of yoga means that "the mere practice of breath-control or of yogic postures is spiritually of little avail" (Jakubczak, 2004, p. 115). Australian Astanga teacher and researcher Benjamin Smith writes that "beyond the development of the physical ability to execute difficult poses, and the calmness of mind required to undertake the practice fully, this 'encounter' with the embodied self brings about moments within asana practice which practitioners identify as 'spiritual'" (2007, p. 40). For dancers, often necessarily very focused on physical aspects of embodiment, the potential exists within yoga to experience methods and opportunities for aesthetic, emotional and spiritual expression. Thus, yoga might offer dancers a method of developing experiences of super-consciousness and integrity through a more meditative and holistic approach to movement in performance. Further, participating in yoga classes may well offer social contact and support within a specific community (Lewis, 2008). And relaxation through movement, breathing and meditation can contribute to the wellbeing of dancers who lead active lives and may have stressful professional careers (Barbour, 2008; Cardinal, 2014). Thus, as Deborah Orr comments, "With yogic meditation techniques such as mindfulness, they [dancers] can bridge the socially constructed gulf between mind and body, feeling and spirit, ideas and life, and self and other that current pedagogy is often unable to span" (2002, p. 494).

Other research lends support to the argument that yoga offers an experience that develops meditation, contemplation, self-reflection, and embodied knowing (Csordas, 1993; Dolan, 2007; Lea, 2009; MacKenzie, 2010). In particular, I am much encouraged by Orr's general statement: “... feminist scholars have theorized that yoga techniques can help women access unoccupied subjective sites from which to mount resistance to oppressive discourses by enabling them to develop forms of self-acceptance uncontaminated by such patriarchal institutions as the beauty industry" (Orr, 2002, p. 483). These statements from researchers working in Western contexts align well with my own feminist and pedagogical commitments to consider wellbeing holistically, in both dance and yoga, as part of consideration of contemporary socio-cultural and political issues for women. ${ }^{v}$ 

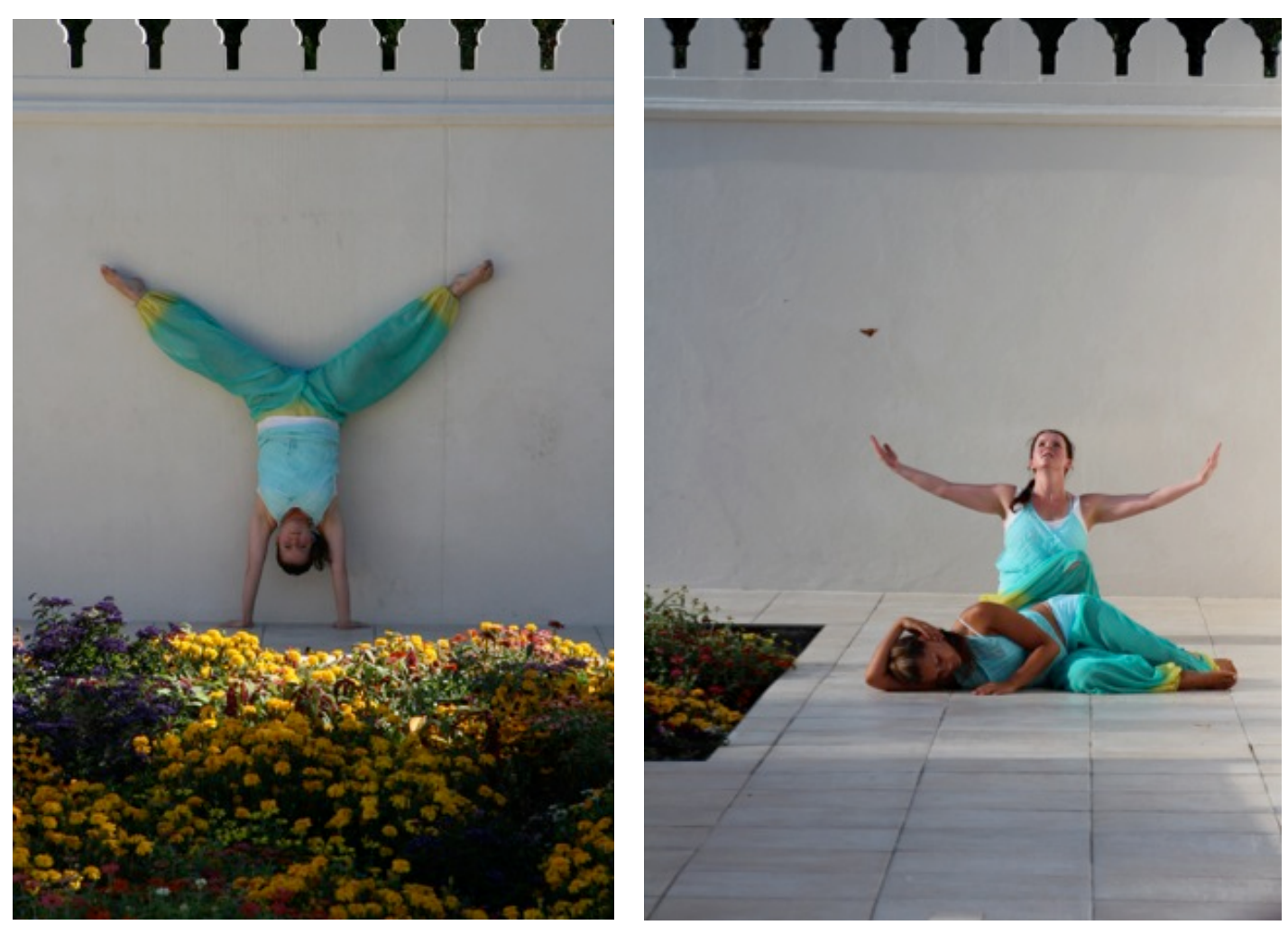

Photograph 1: Marie in Bliss. Photograph by Marcia Mitchley (2013)

Photograph 2: Caterina and Marie in Bliss. Photograph by Molly McCabe (2013)

Thus, I began this specific research project with questions regarding how yoga practices might be developed within choreography for performance, while retaining a focus on wellbeing. Attending to our wellbeing, I am interested in developing an embodied, creative process methodology for use during preparation, rehearsals, sequencing of the movements in the choreography and the choices of specific āsana. While integration of yoga and dance in training is common, considering āsana and yoga principles in the creative process or developing them into performance is less common. vi In this article I describe some of these research experiences with a view to both sharing choreographic research methodologies and prompting consideration of wellbeing for dancers.

\section{CREATIVE PROCESS: PREPARATION}

In developing an embodied methodology for choreographic process, I drew strongly on rituals of practice that benefitted me in dance and yoga as we prepared for performances. Beginning each day with greetings, discussions about our embodied states and experiences, and opportunities for feedback and support became a positive ritual, and this process was continued throughout (Cardinal, 2014; Cheesman, 2011). While arguably not unusual in dance creative processes, it is 
easy to overlook the significance of daily discussion time in terms of social and psychological wellbeing. Preparing for the day, I drew on Sondra Fraleigh's (2009) 'Land to water yoga' developmental movement to foster progressions from our everyday upright movement to the floor and into more common contemporary dance floor warm-up exercises. Integrating yoga principles and āsana into floor work, engaging breath with movement, taking time to investigate, balancing each side of the body, was combined easily with rest periods between activities. Following floor work, regular practice of Suryanamaskara (Sun Salutations-flowing sequences or vinyasa) and standing poses, using the Astanga method and integrating breath allowed us to build strength, focus and capacity over time in this more intensive practice (Fraleigh, 2009). Standing, travelling and partnering exercises common to contemporary dance classes were the next part of the class, although we did fewer of these exercises than I would normally include in a technique class. Imagery to assist in the quality and alignment of the yoga and dance movement was interwoven with instruction, drawing on both in contemporary dance and yoga practices. Closing each preparation class, and the whole day, was a meditative ritual involving simple movements and breathing in a short sequence called 'Salute to Inner Calm'.

Preparing in the dance studio for the creative choreographic process helped me engage as choreographer, being personally more focused and prepared. This process provided the foundation for integrating yoga and contemporary dance to train and attend to details in alignment of yoga movement with the dancers and build our capacity and confidence, especially for those less familiar with yoga. The dancers reflected on their embodied experiences in the preparation aspects of the creative process and the following quotations illustrate their experiences.vii

Caterina: "Maintaining my physical and emotional wellbeing during the choreographic process for Bliss was definitely strongly based on our shared warm ups in the morning. Beginning the rehearsal with floor work, basic natural movement and warming up the spine felt like a very organic way into the body. Followed by repetitions of the Salute to the Sun was the perfect combination to also awake the yogi body, lengthen and strengthen for the choreography that required the yoga foundation."

Helene: "In general the process was easy on the body and mind. We were given ample time to warm up our bodies and awaken our minds. The warm up was a group process to bring us together as a group and prepare us for 
working and performing together as a unity. Attention was given to the individual and to our bodies."

\section{CREATIVE PROCESS: REHEARSALS}

Throughout each day of rehearsal we worked on approaches that integrated yoga āsana and vinyasa directly into our movement and this informed our embodied methodology. Sensing balance within our bodies and repeating movements to develop flexibility and strength evenly required dedicated time during rehearsal (Cardinal, 2014). Offering detail in working in specific āsana, I also discussed and referred to a range of yoga resources to support our practice. Inviting yoga teachers from our community to observe and comment was also helpful for the dancers' confidence and learning. I devoted attention to the tempo of our movement, which often felt slower than normal in contemporary dance, and to the specific garden environment of the choreography. While the choreography was necessarily developed in relation to the garden environment, sometimes our sequences felt too symmetrical in design, or too much unison or too slow for performance tempo. However, as might be anticipated in site-specific dance, our dancerly concerns about slow tempo and symmetry were less important than working harmoniously with the specific garden aesthetics and design (Barbour, 2010). Stimulating consideration of the aesthetics of environment in which we were moving meant allowing more time for us to engage with and appreciate the complementary and sensory aspects of movement, weather, planting, stone work, scents, sounds and design elements.

Throughout we also worked with breathing-consciously considering the need for choreographing breath within movement and enjoying the fresh air and scents of the garden. Working in the environment of the garden contributed greatly to my wellbeing. Sunlight, fresh air, the break from dance studios, and the beauty of the garden design affected me enormously and I believe did so for the others as well. Spending time there each day, eating together and socializing was a significant part of the creative process for us and transformed the rehearsal experience. The comment below encapsulates one dancer's experience and reflects comments made by others. viii

Alex: "I found the lessons in yoga very enhancing for my wellbeing. They help me connect with myself and the natural environment around me, teaching me techniques for relaxing and breathing properly. I also found contact work 
with my dance partner helped me to maintain focus on wellbeing, tuning in to another person, connecting with them and becoming aware of their safety and comfort as well as your own is a fantastic way to maintain and develop focus on wellbeing. I found the entire process very calming and relaxing, because of this, the physical demands of the movement became almost effortless."

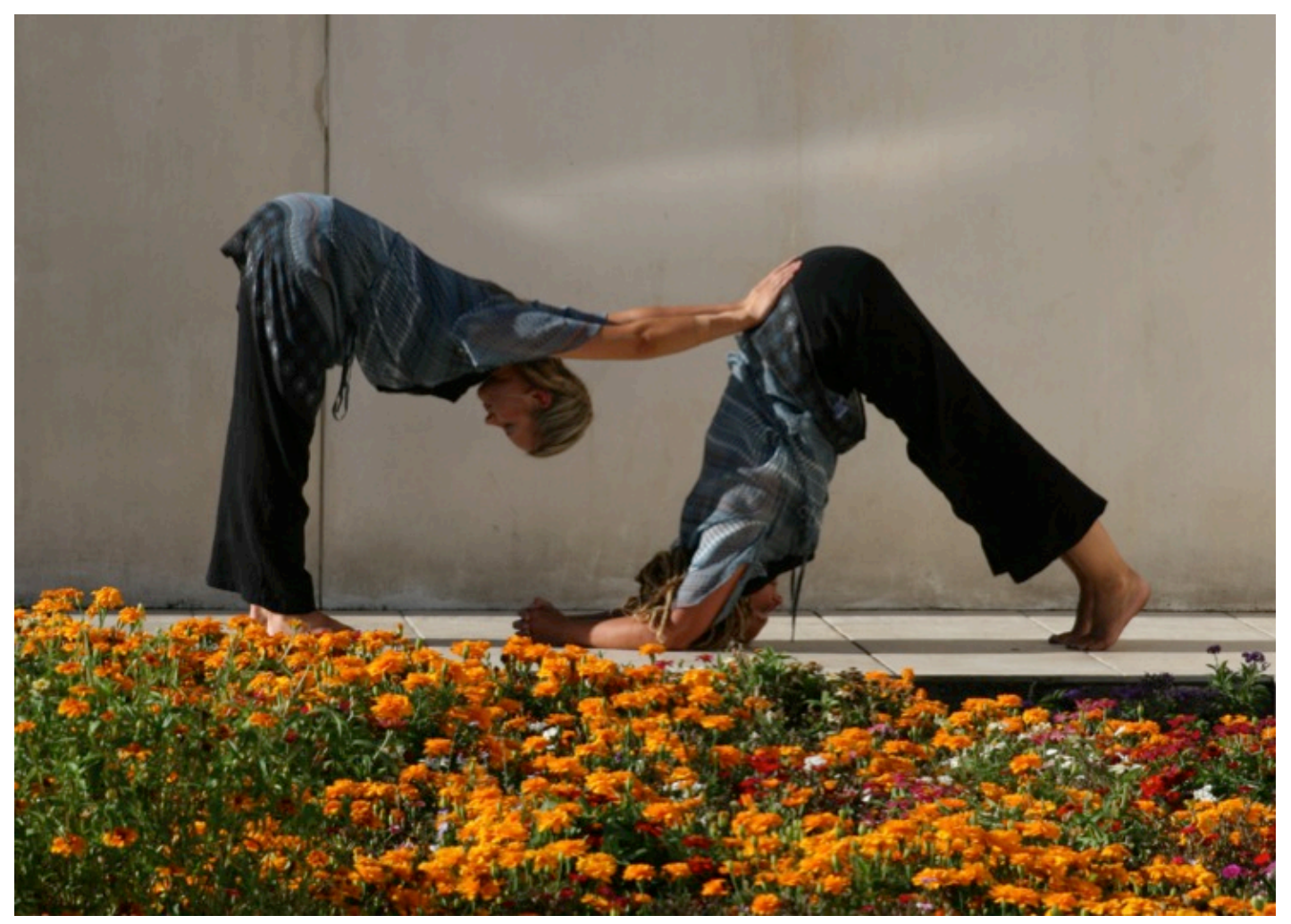

Photograph 3: Alex and Karen in Dancing through paradise. Photograph by Marcia Mitchley (2010)

\section{CREATIVE PROCESS: SEQUENCING FOR PERFORMANCE}

Responsibility for creating the overall choreographic structure of the piece lay with me as choreographer. While paying attention to site-specific considerations in complementing the design of the garden, safety, and creating a performance for the very diverse festival audience, I was also referencing and drawing on the patterns and methods of yoga classes. Reflecting, I identified that many yoga classes begin with acknowledgements, prayer and warm-up, leading into detailed standing and then deeper floor work, with meditation and relaxation to finish. While Astanga yoga has a specific method or sequence within this overall structure, teachers may create themes or develop a particular focus or style as their classes progress. Applying such patterns of yoga classes to performances, I invited the 
dancers to begin seated, present and focused in the space as audience members entered. Acknowledging each other, the garden and the audience in front of the dancers signalled the beginning of the performance. Performing with the support of the walls around the outside of the garden, motifs from Suryanamaskara and standing āsana were included in first sections of the dance. As a student of yoga, I experienced some valuable learning from working with a wall to support balance and alignment in standing poses and inversions (Photograph 1). Thus work along the garden walls was included as a consideration of care for the dancers' practice in performance, as well as creating a strong frieze-like visual effect (Barbour, 2010). These choreographic decisions reflect firstly the process of focusing and giving acknowledgements at the beginning of yoga class and secondly the warm-up and training progressions in yoga practice.

Breathing 'as one', in unison as a group, was introduced as a method for group focus and timing of movement in this warm-up section of the choreography, again as working together as one within Suryanamaskara would be in Astanga practice. Crucial in the choreography throughout, breath was valuable in terms of our timing and transitions through the dancing, but even more important in terms of the significance of breath in practicing yoga with integrity. Keeping a sense of flow and breath through the movement, the next sections of dance were more spacious, involving partnering and contemporary dance travelling sequences to provide dynamic contrasts (Photographs 2 and 4). This faster movement led towards a dynamic high point and then slowed in preparation for the dancers' entrance into the intensive balancing work within the central square of the garden.

Moving with precision, the dancers travelled along narrow marble walkways towards the central fountain, moving fluidly without support through a range of āsana, working in duet as well as quartet (Photograph 6). The theatrical highpoint within the whole dance occurred in the centre of the garden with balancing poses sustained for visual effect. The āsana Maha Natarajaasana (lord of the dance or 'dancer's pose') encompassed a kind of 'ultimate expression' for us, as did the Salute to Inner Calm. Exiting from the central area of the garden allowed each āsana to be repeated to the other side for balance (though not always to the right side first or following the strict sequence in Astanga method).

In Bliss, a new aspect of the partnering work was possible when working with Helene, who has a background in acrobatic gymnastics. Together we were inspired to develop yoga partnering work in a flowing sequence of challenging balances together (Photograph 5). 

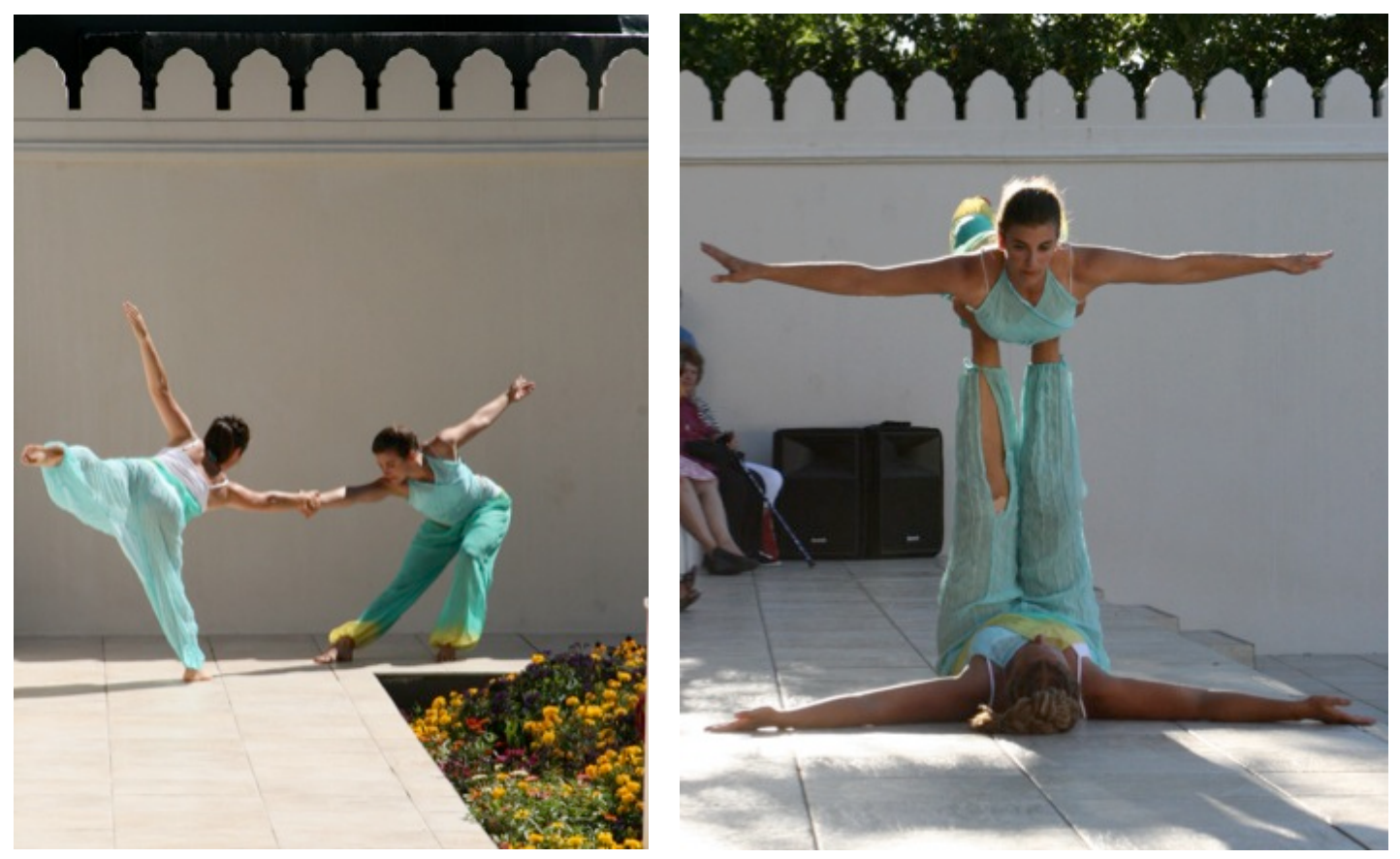

Photograph 4: Patti and Helene in Bliss. Photograph by Marcia Mitchley (2013)

Photograph 5: Karen and Helene in Bliss. Photograph by Marcia Mitchley (2013)

Finally, the dance ended with the whole group coming together, directly in front of the audience with the garden behind us. Movement integrated motifs from throughout the dance and deepened into forward bends and some of the closing sequence of āsana common in yoga classes. The final section was Salute to Inner Calm, performed with the invitation for audience members to join in where they were sitting.

Both Dancing through paradise and Bliss involved referencing many yoga āsana and vinyasa movements and we aimed to perform each with yogic integrity as well as allowing the movements to flow in different sequences and to be integrated with contemporary movement and partnering. Two of the dancers reflected at length on their embodied experiences in the sequencing of the choreography and the relationship to their sense of wellbeing:

Caterina: "The sequencing of the choreography and combination of yoga and dance was very relevant to my wellbeing, within the piece and during the rehearsal process. The sequencing was very related to the space, and choices we made such as sitting in a conscious but meditative manner in the space while the audience walked into the garden and were seated behind us. That way, we were in control of setting the mood in the space and were able to greet people silently ... that part became very significant to set my focus on 
the performance and feeling calm, which was essential for this piece. The sequencing of the movements/structure was very significant for my wellbeing and maintaining my energy throughout the piece. Beginning with strong movements that were supported by the wall was a fabulous way into the performing yogi body and establishing balance, flexibility and strength. Then we continued to stabilize each other with duets and loosened it up with a short contemporary dance sequence, followed by the challenging balancing acts in the centre. Yet this was also one of the most meditative and spiritual moments during the performance and that I enjoyed immensely."

Marie: "The process was, as always, well managed and I felt like I was taken care of. I think the yoga training absolutely helped, and it was a very good idea to start with the more demanding parts like the wall work. It really needed time to sink in... The way the piece was structured made a huge difference to me. A challenging, but slow beginning that focused on bringing us together in unison and breath, followed by for me a more familiar and highly enjoyable contact sequence, which also set me up for the following challenge of the [centre] square."

\section{CREATIVE PROCESS: SPECIFIC ĀSANA}

Specific āsana and vinyasa were key to the choreography. As mentioned already, motifs from both Suryanamaskara and Salute to Inner Calm were key within the choreography. As another example, I will discuss Maha Natarajāsana or 'dancer's pose', which I described above as an 'ultimate expression' for us (Photograph 6). Sondra Fraleigh outlines the benefits of this āsana, commenting that a challenge is "balancing with the back in extension while reaching outward into space ... Focusing the eyes for balance ... Developing courage in a challenging posture and practicing self-forgiveness in occasional loss of balance" are all important (2009, p. 14). One of the reasons I observe that this āsana is an exceptional challenge for dancers is in maintaining a balance between the forward reach (in our case, a curving reach) and the extension through the back, while still keeping the parallel leg alignment of yoga. I have observed that this āsana is particularly difficult for contemporary dancers used to working through rotation in the hip joint and often pushing to the ends of flexibility and capacity in performance. I found myself reminding the dancers to allow that working through these āsana is a long-term journey, to keep a sense of containment and safety in the pose and to breathe. 
Thus, rather than push everyone to an extreme àsana, we moderated within the group to find a sustainable balance. This more moderate approach required a depth of somatic awareness from the dancers and became a way of working with functional integrity in performance. In Bliss, the second and more developed work, the dancers were more experienced and confident in their embodied awareness. Photograph 6 (below) illustrates a moment in the dancers' somatic approach to moving and breathing through Maha Natarajāsana.

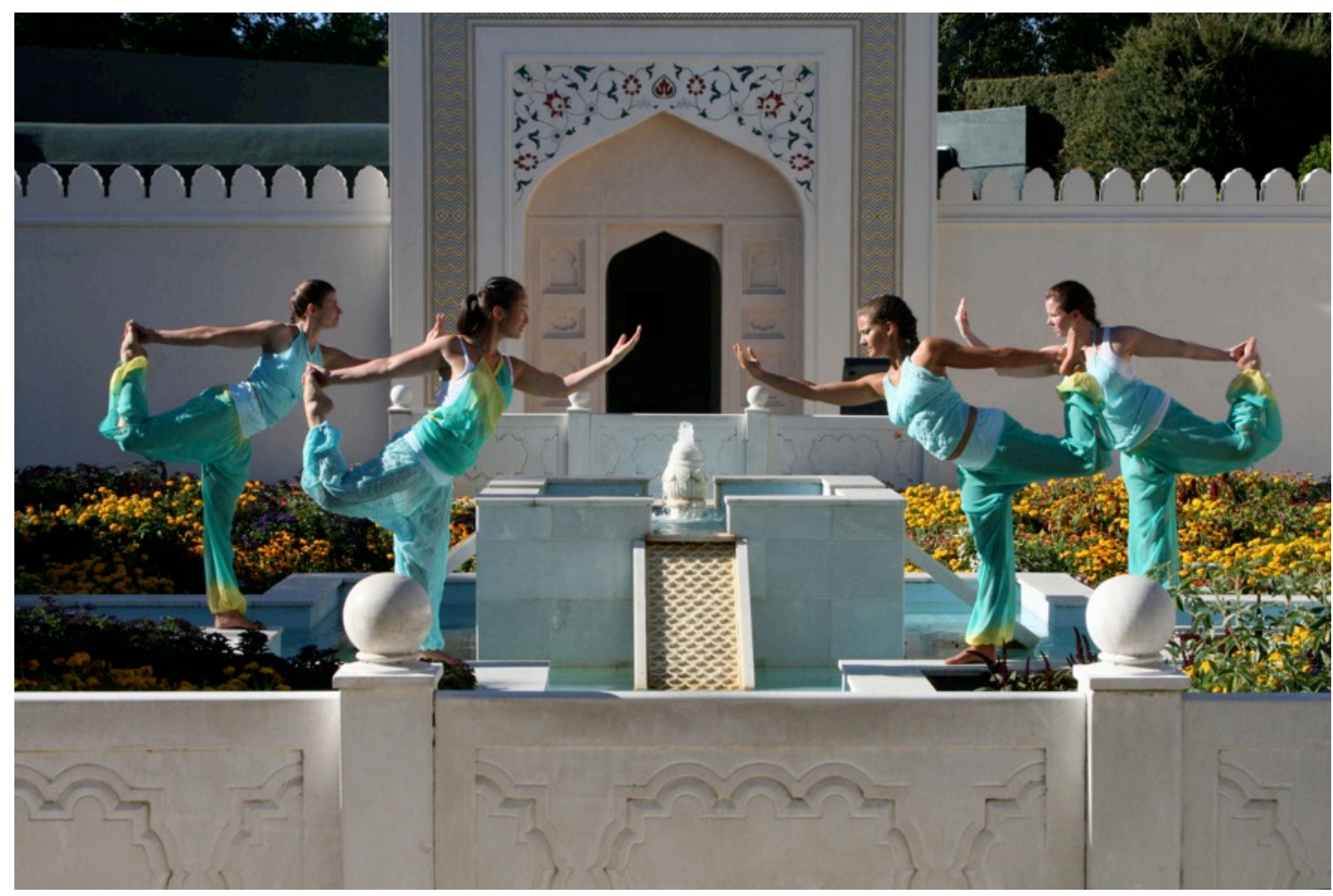

Photograph 6: Helene, Patti, Caterina and Marie in Bliss. Photograph by Marcia Mitchley (2013)

\section{DISCUSSION OF CHALLENGES AND INSIGHTS}

Throughout creating and performing Dancing through paradise (2010) and Bliss (2013), there were a number of challenges to address in the choreographic process and in performance. Pragmatically, many social challenges related to rehearsing in a public space and working with an interested audience of tourists keen to ask questions and unintentionally interrupting our creative processes. These challenges were anticipated as part of working towards site-specific performance but nevertheless unfamiliar to dancers used to a private studio creative and rehearsal process (Barbour, 2010). There were also the challenges of working in the sun and on marble and stone tiles. As choreographer, I did not include any jumping or running movement at all to protect our ankles and knees. I did, however, engage 
us all in inversions and āsana requiring strength in our upper bodies. Creating Dancing through paradise (2010), we noticed the strain in our wrists and shoulders and subsequently when creating Bliss, I ensured that we trained more specifically to develop strength, confidence and functional alignment, particularly in these inversions. The dancers commented on the social, embodied and environmental challenges of working in the garden and these quotations reflect a range of their embodied experiences.

Patti: "It was challenging-having to find and re-find balance and focus in self. [And the] stuff that comes with site-specific practice, heat, sun, public in performance/rehearsal space ... In performance it's weird thinking about my external shape. It contradicts the yoga and tips between how it looks and how it feels. Because of the transitions I journeyed through moments of poses, whereas in yoga I can take the time to revisit, explore and shape a pose and the exploration of the dynamic experience in my body and how it feels."

Helene: "I remember having a bruise on the top of my head after having rehearsed the headstand sequence a lot the previous afternoon. The marble floor did not help in this aspect. But being able to adjust the form made for a pleasant and a lot less painful rehearsal experience. Because the piece is slow moving, even though difficult in places, there was enough time during rehearsal and also during performance to recover from the more strenuous parts of the piece."

Caterina: "The only challenge to keep physical wellbeing was to rehearse on the marble floor in the gardens. The ground doesn't have any give but already after the second rehearsal the body adjusted to the new environment and we learned how to move in the space."

More significant for discussion in this context were concerns about 'performing' yoga well and experiencing the movement, and thus the issue of integrity arose. As a dancer, student of yoga and dance educator, I have been very interested in the idea of functional integrity, valuing and embodying safe dance practice, balance, sustainability and consistency in movement techniques and performance. Addressing functional concerns about safety and movement technique as we worked through the choreography was valuable. When I asked the dancers about their experiences of functional integrity, their sense was that they 
enhanced body awareness, strength and flexibility through the integration of yoga and dance. Quotations below illustrate their reflections on embodied experiences.

Alex: "Experimenting with yoga-based movement did encourage me to look at my body lines and the shapes my body created, and in turn lead to me being more in tune with my body and its abilities. I guess, in a sense, becoming aware of what I can do and being proud of this contributed to my emotional awareness also. I am a lot more confident with yoga and dance integrated movement now, and I naturally follow correct technique and safety measures."

Marie: "I think it also was very helpful to have had yoga teachers comment on the piece in rehearsal, so I felt comfortable that I wasn't doing the form injustice. I loved the feeling of dancing, as opposed to doing, yoga."

Caterina: "I felt a huge growth on all of these aspects, body awareness and a clearer direction of movement. Strength and flexibility definitely increased over that period and overall I felt emotionally very balanced, at peace and completely connected to our work."

Helene: "While rehearsing for Bliss, I realised that my sense of body awareness was lacking somewhat. Because yoga is very precise in the lines and angles your body makes, you need to be very aware of what your body is doing. In the studio this is a bit easier to achieve, because of the mirror. Selfcorrection was possible. Outside in the garden this was a different story ... just your memory in the body ... [and I] wasn't fully aware how poses are supposed to feel in [my] body ... I realised I hadn't achieved this body awareness as I would have liked to, but I do think it has improved."

Patti: "Yes I experience all of those things in yoga, not all at once, and I have to keep finding it over and over again."

In yoga as in life, I understand integrity more broadly than just functional movement integrity. Integrity more broadly reflects consistency in actions and values. Thus in performing, the integrity of a dancer seems to me to be clearest when the dancer has a very strong belief in the value of their moving, is consistent in their movement and is able to reveal that belief to me as I watch so that I too can appreciate and experience the value of their moving. Consequently, if we were to 'perform' the yoga āsana without engaging fully in the embodied and somatic 
experience of the movement we would be compromising our integrity. Engaging not only through the physical shapes and forms, we also needed to be fully present-emotionally, intellectually and spiritually present in our embodiment.

A further challenge arose in balancing on the narrow marble walkways within the central garden area. Surrounded by flowerbeds and water, there was a very real risk of injury if anyone fell on the walkways. With balancing āsana, particularly Maha Natarajāsana or 'dancer's pose', Fraleigh recommends "accepting the experience of teetering and letting go of blame-gathering up the posture in ever-new approximations of the dance" (2009, p. 15). Early in the rehearsal process I introduced a practice of 'self-forgiveness' to encourage everyone to work sustainably within her capability and develop safe balances throughout the process. This process fostered functional integrity and no one ever actually fell or was injured. However, the perceived risk of falling and the emotional challenge of dealing with risk required working with balanced postures and moderation within the group. Marie's statement that "the balance work was a challenge for me, and I am still practicing forgiveness" encapsulated the dancers' ongoing engagements with this practice of forgiveness. Patti also commented on her experience of finding herself over and over-a comment that recalls the notion of wellbeing as a dynamic dance.

The quotations from the dancers included throughout this paper connect to the broader feminist agendas I bring into education and specifically to working in choreographic practice, in the sense that the dancers are supported to critically reflect on their embodied awareness and wellbeing. These agendas reflect my feminist ethic of care in creative practice and research; an agenda concerning our relationships, empowerment and transformation, rather than therapy per se. In the quotations above, Alex, Caterina and Helene identify growing body awareness and confidence, drawing on technique, safety and strength, and moving beyond a focus on their outward shape or form towards a more embodied experience of the movement. Thus they indicate they were present in rehearsing and performing, reflexive in the moment and acting with consistency. Further, Alex and Caterina both comment on growing emotional awareness, and a sense of balance, integration and connection in moving. Recalling Deborah Orr's (2002) suggestion that yoga may enable women to resist oppressive and stereotypical discourses of the body as promoted through the beauty industry, I suggest that the embodied integration of yoga and dance empowered the dancers to engage in the moment in their embodied experiences, to celebrate their experiences as dancers, to perform 
with integrity, and to practice self-forgiveness and self-acceptance. Engaging in performing beyond concerns purely about their outward form, the dancers were instead expressing more of their unique potential in these dynamic dances of wellbeing. Consequently, I suggest that they were actively embodying alternative subjective positions as women and as dancers.

A further discussion point concerns the emergence of experiences of bliss through the integration of yoga and dance in this research. In yoga traditions, the 'end' of the yogic quest is the experience of samādhi in meditation, during which the senses and the body are at rest and the person is "fully conscious and alert" (lyengar, 1994, p. 52). In this state, the person experiences "consciousness, truth and unutterable joy" (lyengar, 1994, p. 52) and exists in a state of meditative super-consciousness in which everything is merged and blended together in the moment (Desikachar, 1995; lyengar, 1994). In samādhi, the yogi experiences a "state of meditation in which only the object of meditation is apparent" (Desikachar, 1995, p. 241). lyengar commented that "contentment gives bliss unsurpassed to the yogi ... Contentment and tranquility are states of mind" (2001, p. 37) and through the method of yoga "the mind, when controlled, provides a reservoir of peace and generates abundant energy for human uplift" (lyengar, 1994, p. 20).

As part of the choreographic and performance process, we discussed the potential for moments of 'bliss' to occur within our performing, although we did not necessarily consider this an ultimate choreographic agenda. Discussing the Song of the Soul (sung by Sankarāchārya in Ātma Satkam), we were drawn particularly to the last lines, which read:

"Ever serenely balanced, I am neither free nor bound-

Consciousness and joy am I, and Bliss is where I am found." (lyengar, 1994, p. 53)

In both yoga and dancing, we had each had personal and unique experiences of 'bliss', including tranquil experiences and experiences that were more exhilarating (Gold, 2013). Discussing what bliss might mean generally during rehearsals, we drew on varied experiences throughout our lives, while not intending to reductively define what bliss might be. We imagined that emergent experiences of bliss in the garden might contribute to our wellbeing, to the generation of energy and also to a sense of peace. Thus we were open to such altered and uplifting experiences of bliss, of joy, peace and contentment, in 
performing. While difficult to express these unique moments in words, some comments from the dancers nevertheless offer insight into their embodied experiences of bliss in Dancing through paradise and Bliss.

Alex: "I really do believe that performing Dancing through paradise, in all the beauty of the garden, with the sun beaming down, butterflies floating past and an audience smiling at me, was an experience of bliss."

Marie: "As Caterina and I stepped over into the square followed by a high arch to the clear blue sky and a small breeze came through, I experienced bliss."

Patti: "Bliss (in this context) was feeling contained and confident, strong, ease and control."

Caterina: "My confidence in the movement vocabulary both in yoga and dance grew strongly over the period, and the sensation of both coming together in one work was such a unique experience, that I felt pure bliss on a physical level, spiritual, mentally and as a whole moving body of energy."

Karen: "I felt joy in performing in the first sections of the dance involving breathing as one and suspended inversions. I didn't perform in the middle sections of the dance and instead I sat 'holding the space', watching and supporting, breathing and meditating as the other dancers performed. The movement was all very familiar in my body and I felt a tangible sense of the movement empathetically-I could actually feel the poses, the balancing, the weight of my body when I watched the other dancers. As I sat, legs crossed, breathing consciously while the dancers performed inside the garden around the fountain, I felt myself supporting their balance and breath as I watched. I felt connected and at peace within their dancing."

Performing live, we are aware of the potential for our embodied emotional experiences to affectively stimulate kinesthetic responses in audience members (Barbour \& Hitchmough, 2013). Articulating these affective experiences in words is challenging. Some of the photographs included in this article offer another means of representing such moments of bliss and may potentially stimulate a sense of our embodied experiences for readers. 


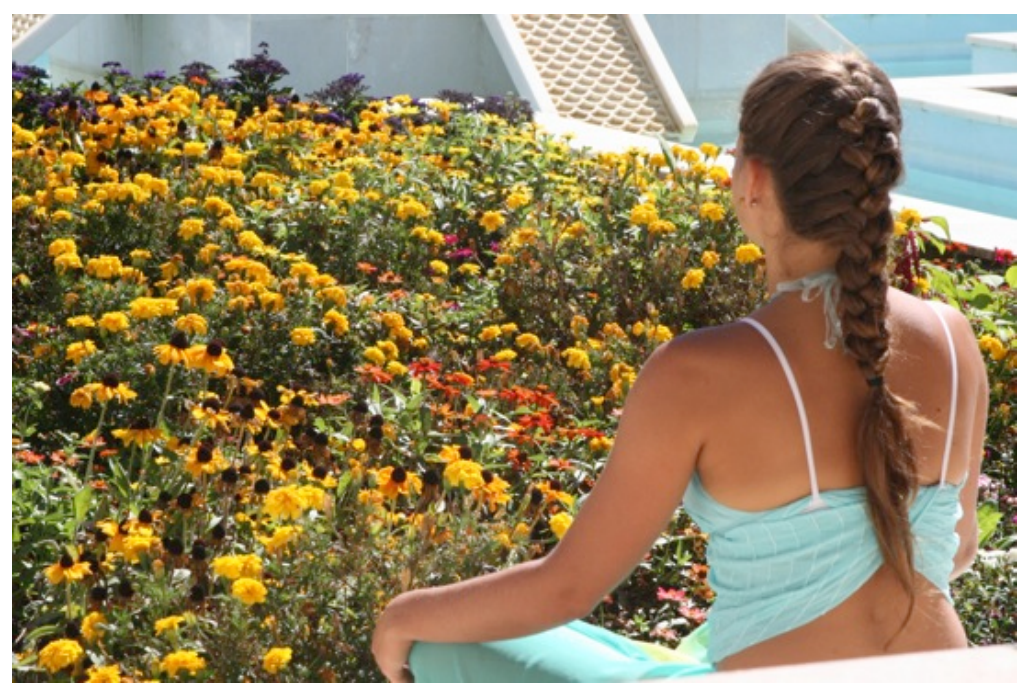

Photograph 7: Caterina in Bliss. Photograph by Marcia Mitchley (2013)

\section{CONCLUSIONS}

Researching the integration of yoga-based movement motifs within choreography for performance drew on our experiences in the creation of two festival performance works. For the dancers in our group, including myself, simply dancing and being able to perform together contributes to our sense of wellbeing. As we engage socially with other dancers, find means of self-expression, deepen awareness, participate in the embodied experience of moving and the stimulation of ideas and emotions within the creative process, we become more engaged and responsive as members of our community. Positively, the further aim to consider wellbeing in this research led me to consider how the choreographic process as a whole could foster wellbeing, drawing on a feminist ethic of care. Preparation and creative processes, the choices and sequencing of yoga-based movements in the choreography, and the inclusion of specific āsana, all offered insights and challenges.

Throughout this research, each of us participated in a dynamic dance, balancing the resources we had to respond to the challenges we faced. We discovered ways to build and sustain our capacity as we worked, drawing on our environment and each other as well as on the yoga principles of breath and moving meditation, as we faced challenges in our dynamic dance of wellbeing. These discoveries brought recognition of our deepening embodiment of contemporary dance and yoga, and provided a way of practicing self-forgiveness, self-acceptance and integrity within our lives. Thus, the creative processes and performance experiences offered more than simply dancing. In our own ways, the opportunity 
arose to enhance our wellbeing within the creative process and to delight in moments of bliss.

\section{REFERENCES}

Barbour, K. N. (June 2008). Sustainable dance making: Dancers and choreographers in collaboration. Brolga, 28, 40-51.

Barbour, K N. (2010). Engaging delight: A case study of site-specific dance in public city gardens. The International Journal of the Arts in Society, 5(3), 119-135.

Barbour, K. N. (2011). Dancing across the page: Narrative and embodied ways of knowing. Bristol, England: Intellect Books.

Barbour, K. N. (2013). Cultivating embodied ways of knowing: Integrating contemporary dance and yoga practice in tertiary education.. In Close Encounters. Contemporary Dance Didactics: Exploration in Theory and Practice; Proceedings (pp.105-116). Stockholm, Sweden: University of Dance and Circus.

Barbour, K. N., \& Hitchmough, A. (2013). Experiencing affect through site-specific dance. Emotion, Space and Society. DOI: 10.1016/j.emospa.2013.11.004 http://dx.doi.org.ezproxy.waikato.ac.nz/10.1016/j.emospa.2013.11.004

Bennett, B. (2002). Emotional yoga: How the body can heal the mind. Sydney, NSW, Australia: Bantam Books.

Cardinal, M. K. (2014). SPICE ${ }^{2}$ S: Wellness dimensions applied to dance with advice for teachers. Journal of Physical Education, Recreation and Dance, 85(3), 3-7.

Cheesman, S. (2011). Facilitating dance making from a teacher's perspective within a community integrated dance class. Research in Dance Education, 12(1), 29-40. doi: $10.1080 / 14647893.2011 .554976$

Csordas, T. J. (1993). Somatic modes of attention. Cultural Anthropology, 8(2), 135-56.

Dalzell, J. (2011). How I teach yoga for dancers. Dance Teacher, 33(3), 36-38.

De Michelis, E. (2010). History of modern yoga: Patanjali and Western esotericism. London: Continuum International Publishing.

Desikachar, T. K. V. (1995). The heart of yoga: Developing a personal practice. Rochester, VT: Inner Traditions International.

Dodge, R., Daly, A. P., Huyton, J., \& Sanders, L. D. (2012). The challenge of defining wellbeing. International Journal of Wellbeing, 2(3), 222-235.

Dolan, M. (2007). A new transformation in higher education: Benefits of yoga and meditation. International Forum of Teaching and Studies, 3(1), 31-36.

Doube, G. (2007). Feature garden: Hamilton Gardens, Hamilton New Zealand. The Botanic Garden, 17, 11-17.

Durie, M. (1994). Whaiora: Māori health development. Auckland, New Zealand: Oxford University Press

Enghausser, R. (2007). Developing listening bodies in the dance techniques class. Journal of Physical Education, Recreation \& Dance, 78(6), 33-37, 54.

Fraleigh, S. (2009). Land to water yoga. Shin somatics moving way. Bloomington, IN: iUniverse.

Gesler, W. (2003). Healing places. Oxford, England: Rowman \& Littlefield.

Gold, L. (2013). Altered experience in dance/dancing: Investigation into the nature of altered experience in dancing and pedagogical support. Helsinki, Finland: Acta Scenica.

Greer, G. (1999). The whole woman. London, England: Anchor.

Hartley, L. (1989). Wisdom of the body moving: An introduction to body-mind centering. Berkeley, CA: North Atlantic Books.

lyengar, B. K. S. (1994). Light on yoga: Yoga dipika (Rev. ed.). New York, NY: Schocken Books.

Jakubczak, M. (2004). Towards knowing ourselves: Classical yoga perspective. Journal of Human Values, 10(2), 111-116.

Lea, J. (2008). Retreating to nature: Rethinking "therapeutic landscapes". Area, 40(1), 9098. 
Lea, J. (2009). Liberation or limitation. Understanding lyengar yoga as a practice of the self. Body \& Society, 15(3), 71-92.

Lewis, C. S. (2008). Life chances and wellness: Meaning and motivation in the "yoga market". Sport in Society: Culture, Commerce, Media, Politics, 11(5), 535-545.

Macdonald, M. (1995). Representing women: Myths of femininity in the popular media. London, England: Edward Arnold.

MacKenzie, S. K. (2010). Disciplined (un)knowing: The pedagogical possibilities of yogic research as praxis. The Qualitative Report, 15(5), 1124-1144.

Noddings, N. (2003). Caring: A feminine approach to ethics and moral education. Berkeley, CA: University of California Press.

Orr, D. (2002). The uses of mindfulness in anti-oppressive pedagogies: Philosophy and praxis. Canadian Journal of Education/Revue canadienne de l'education, 27(4), 477497.

Santillano, S. R. (2006). The effects of hatha yoga on contemporary dance: Pitfalls, practices, and possibilities (Unpublished masters thesis). Wesleyan University, Middleton, CT.

Sergel, P. (2004). Inspiration in the garden. Auckland, New Zealand: Viking.

Smith, B. R. (2007). Body, mind and spirit? Towards an analysis of the practice of yoga. Body \& Society, 13(2), 25-46.

World Health Organisation. (1997). WHOQOL Measuring quality of life. Geneva, Switzerland: Author.

\footnotetext{
${ }^{i}$ A detailed discussion of the differences in the modern lyengar and Astanga yoga practices is beyond the scope of this paper. Both are forms of 'Modern Yoga' (De Michelis, 2010). Patanajali's Yoga Sūtra provides a classical text to which both B. K. S lyengar and his teacher Srī T. Krishnamacharya refer, as do those who practice Astānga yoga and follow the teacher Srī K. Pattabhi Jois. The most obvious differences to practitioners like myself is that those working with an Astanga practice include more flowing and continuous vinyasa (flowing sequences in a specific order), whereas a slower focus on the technique of various āsana (poses or postures) is common in lyengar classes. Further, Srī K. Pattabhi Jois created a base in the Astanga Yoga Research Institute in Mysore, India, whereas B. K. S lyengar developed a step-by-step method through his writings and teachings for Westerners.

ii Ethical approval was granted for these research projects by the Faculty of Education Ethics Committee of The University of Waikato.

iii Patti Mitchley, Alex Hitchmough, Emma Goldsworthy and Karen Barbour were the performers in Dancing through paradise (2010) and Caterina Laschke, Helene Burgstaller, Marie Hermo Jensen, Patti and Karen were the performers in Bliss (2013).

${ }^{\text {iv }}$ For a discussion of site-specific dance (including discussion of Dancing through paradise), see Barbour (2010, 2011) and Barbour \& Hitchmough (2013).

${ }^{\vee}$ The impact of stereotypical media representations of femininity on women and specifically on dancers has been, and continues to be, the subject of much discussion and research. For examples and discussion of issues, see Barbour (2011), Greer (1999) and Macdonald (1995).

vi California's The Yoga Garden is one company that specialises in choreography based on performing hatha yoga. Director Gay White describes: "Blending music with movement and yoga asanas, we are inspired by the spirit of yoga but are informed by contemporary modern dance" http://yogagarden.org

vii I have selected two or three quotations from the dancers' reflections on their embodied experiences to illustrate the 'data' obtained in the research.

viii I have selected one quotation as illustrative of the findings obtained in the research. In this case, as with other findings, the photographic images add to or reinforce the dancers' reflections.
} 